\title{
Serum uromodulin and progression of kidney disease in patients with chronic kidney disease
}

\author{
$\mathrm{Li} \mathrm{Lv}^{1,2 \dagger}$, Jinwei Wang ${ }^{1 \dagger}$, Bixia Gao ${ }^{1 \dagger}$, Liang Wu${ }^{1}$, Fang Wang ${ }^{1}$, Zhao Cui ${ }^{1}$, Kevin He ${ }^{3}$, Luxia Zhang ${ }^{1,4^{*}}$, Min Chen ${ }^{{ }^{*}}$ \\ and Ming-Hui Zhao ${ }^{1,5}$
}

\begin{abstract}
Background: Uromodulin is specifically synthesized and secreted by kidney tubular epithelial cells. Studies on the association of serum uromodulin and outcomes of chronic kidney disease (CKD) are lacking. This study aimed to evaluate whether serum uromodulin was associated with outcomes of patients with CKD.

Methods: We measured serum uromodulin concentrations by ELISA in 2652 CKD patients from the Chinese Cohort Study of Chronic Kidney Disease (C-STRIDE) and investigated the association of serum uromodulin with outcomes of CKD patients, including end-stage kidney disease (ESKD) receiving kidney replacement therapy, cardiovascular events and mortality by Cox proportional hazards regression model.

Results: A total of 2652 CKD patients were enrolled in this study, with an age of $48.7 \pm 13.8$ years and the baseline eGFR of $49.6 \pm 29.4 \mathrm{~mL} / \mathrm{min} / 1.73 \mathrm{~m}^{2}$, of whom $58.4 \%$ were male. The median level of urinary albumin/creatinine ratio and serum uromodulin was $473.7 \mathrm{mg} / \mathrm{g}$ (IQR $134.1-1046.6 \mathrm{mg} / \mathrm{g}$ ) and $77.2 \mathrm{ng} / \mathrm{mL}$ (IQR 48.3-125.9 ng/mL), respectively. Altogether, 404 ESKD, 189 cardiovascular events, and 69 deaths occurred during the median follow-up of 53.6 (IQR 44.0-64.0) months. Lower levels of serum uromodulin were independently associated with higher risk of incident ESKD after adjusting for traditional cardiovascular risk factors, with the hazard ratios (HRs) of 3.23 (95\% confidence intervals [Cls] 2.15-4.85) for the middle tertile and 7.47 (95\% Cl 5.06-11.03) for the bottom tertile, compared with top tertile and 0.31 ( $95 \% \mathrm{Cl} 0.25-0.38$ ) per every standard deviation increase. After further adjustment for the baseline eGFR, the association was greatly attenuated, but still significant, with HRs of 1.92 (95\% Cl 1.26-2.90) for the bottom tertile compared with top tertile and 0.69 (95\% Cl 0.55-0.86) per every standard deviation increase.
\end{abstract}

Conclusions: Serum uromodulin is independently associated with an increased risk of incident ESKD in CKD patients. Keywords: Uromodulin, Chronic kidney disease, Outcomes

\section{Background}

Chronic kidney disease (CKD), with a high prevalence of over $10 \%$, is one of the leading global public health problems [1]. In addition to progression to end-stage kidney

\footnotetext{
*Correspondence: zhanglx@bjmu.edu.cn; chenmin74@sina.com

${ }^{\dagger} \mathrm{Li}$ LV , Jinwei Wang and Bixia Gao contributed equally to this paper

${ }^{1}$ Renal Division, Department of Medicine, Peking University First Hospital; Institute of Nephrology, Peking University; Key Laboratory of Renal Disease, Ministry of Health of China; Key Laboratory of Chronic Kidney Disease Prevention and Treatment (Peking University), Ministry of Education, Beijing 100034, China

Full list of author information is available at the end of the article
}

disease (ESKD), patients with CKD are at high risk for cardiovascular disease and mortality [2]. It is thus particularly important to distinguish high-risk CKD patients. To date, biomarkers for evaluating the risk of CKD progression are restricted to the estimated glomerular filtration rate (eGFR) and proteinuria; these cannot fully reflect the tubulointerstitial function or the heterogeneity of CKD progression. Based on some previous studies, tubulointerstitial lesions might be more important for predicting kidney disease progression than glomerular and vascular lesions in patients with various kidney diseases [3-6]. The status of tubulointerstitium might better 
reflect total nephron mass and therefore could be helpful for identifying high-risk CKD patients more precisely. However, such kinds of markers are not well-established.

Uromodulin is the most abundant protein in urine [7-9] and is specifically synthesized and secreted by kidney tubular epithelial cells. Rare mutations in the UMOD gene have been described as a cause of hereditary autosomal-dominant tubulointerstitial diseases $[10,11]$. Wellknown genome-wide association studies (GWAS) have successfully identified common variants in the $U M O D$ gene as risk factors for CKD and hypertension in the general population [12-14]. Recently, some prospective studies showed that serum uromodulin levels were independently associated with the risk of cardiovascular event and mortality as well as decline in kidney function among patients referred to angiography [15-17]. It is not yet known whether serum uromodulin was associated with outcomes of CKD patients. Hence, in the current study, we measured the serum uromodulin levels and investigated the association of serum uromodulin with kidney function and outcomes of CKD in a large, multicenter prospective cohort study of CKD patients, the Chinese Cohort Study of Chronic Kidney Disease (C-STRIDE).

\section{Methods}

\section{Participants}

The C-STRIDE is a multicenter prospective cohort of CKD patients, containing 39 clinical centers in different geographic regions of China. The criteria for the enrollment of participants are listed in Additional file 1. CKD participants have been enrolled from November 2011, a total of 3499 patients have completed screening until 30 June 2016, of which 686 patients were excluded due to missing values of serum creatinine and/or loss of followup data, altogether 2813 patients have the completed baseline and follow-up data. Due to the availability of the biosamples for measuring serum uromodulin, therefore, 2652 patients were included in the present study. For the etiologic diagnosis, there were 1707 patients with glomerular diseases, 547 patients with tubulointerstitial diseases and 398 patients with other or unknown causes. The design of C-STRIDE has been described elsewhere in detail [18].

\section{Study design}

We measured serum uromodulin levels of 2652 CKD patients at baseline and described the distribution of baseline data of these patients according to serum uromodulin levels. Then, we further investigated the associations of serum uromodulin with pre-specified end-points of CKD patients, including ESKD, cardiovascular events and all-cause mortality. The baseline data included detailed demographics, underlying disease, behavioral habits, medical and medication history, anthropometric measures (height, weight, resting blood pressure), chemistry indexes (triglyceride, total cholesterol, low-density lipoprotein cholesterol, high-density lipoprotein cholesterol, fasting blood glucose, prealbumin, serum creatinine, high-sensitivity C-reactive protein), and urinary albumin/creatinine ratio. The end-point events of CKD patients were collected before 30 June 2017. All these patients gave written informed consent before data collection. The study was approved by the Ethics Committee of Peking University First Hospital and was in adherence with the Declaration of Helsinki.

\section{Detection of serum uromodulin by enzyme-linked immunosorbent assay (ELISA)}

Fasting venous blood samples were obtained at the study visit. All participants' blood samples were transported by cold chain to the Central Laboratory of Peking University First Hospital and stored at $-80{ }^{\circ} \mathrm{C}$ until use. Serum uromodulin was measured in batches from stored material in the Central Laboratory of Peking University First Hospital from May 2016 to August 2016. We measured serum uromodulin by a commercially available ELISA kit (Euroimmun AG, Lübeck, Germany) according to the manufacturer's instructions. The process of the assay was described in Additional file 1.

\section{Measurement of covariates}

The covariates in the multivariable models were either potential confounders, or the independent predictors of the adverse outcomes. All blood and urine samples were analyzed in the Central Laboratory of Peking University First Hospital to avoid the variation of testing values between laboratories. Serum total, low-density lipoprotein, and high-density lipoprotein cholesterol, triglycerides were measured with commercially available reagents. Urinary albumin and creatinine were measured from a fresh morning spot urine sample or morning urine sample stored at $4{ }^{\circ} \mathrm{C}$ for less than 1 week. Albuminuria was measured with immunoturbidimetric tests. Urinary creatinine was measured with the ammonia iminohydrolase method. The urinary albumin to creatinine ratio (mg/g creatinine) was calculated. Serum creatinine was measured by the same methods as urinary creatinine. The eGFR was evaluated by the equation developed by adaptation of the Modification of Diet in Renal Disease (MDRD) equation on the basis of data from the Chinese CKD participants: eGFR $=175 \times($ serum creatinine [in $\mu \mathrm{mol} / \mathrm{L}] / 88.4)^{-1.234} \times \mathrm{age}^{-0.179} \times($ if female $\times 0.79) \quad[19]$. All eGFR values of more than $120 \mathrm{~mL} / \mathrm{min} / 1.73 \mathrm{~m}^{2}$ were set at $120 \mathrm{~mL} / \mathrm{min} / 1.73 \mathrm{~m}^{2}$.

Body mass index was calculated by using the following formula: weight $(\mathrm{kg}) /$ height $^{2}\left(\mathrm{~m}^{2}\right)$. Blood pressure 
was measured three times at 5-min intervals by a sphygmomanometer. The mean value of the three readings was calculated. The use of anti-hypertensive medications in the past 2 weeks before baseline examination was recorded. Diabetes was defined as the fasting plasma glucose of $7.0 \mathrm{mmol} / \mathrm{L}$ or more, or the use of hypoglycemic agents or a self-reported history of diabetes.

\section{Study outcomes}

The pre-specified end-point events of the CKD patients included ESKD, cardiovascular event, and all-cause mortality. ESKD is defined as the initiation of chronic dialysis or renal kidney transplantation or irreversible development of eGFR $<15 \mathrm{~mL} / \mathrm{min} / 1.73 \mathrm{~m}^{2}$. All the ESKD events included in the current study have initiated hemodialysis, or peritoneal dialysis, or kidney transplantation. Cardiovascular events included acute myocardial infarction, unstable angina, hospitalization for congestive heart failure, cerebrovascular events (intraparenchymal hemorrhage, subarachnoid hemorrhage, cerebral infarction, etc.), and peripheral vascular diseases. Echocardiogram and electrocardiogram examination were requested in the validation of cardiovascular events; however, cardioangiography was not routinely performed. Only one event per patient was included in the current analysis. Finally, we separately evaluated the associations of baseline serum uromodulin with different clinical outcomes of CKD patients, including ESKD, cardiovascular events and all-cause mortality.

The end-point events were collected at 3- to 6-month intervals until 30 June 2017 in the current analysis. The director at each clinical center asked for end-point events according to the new-onset events registration form either by phone calls or routine clinical visits. Once the end-point events occurred, the director at the clinical center filled out the new-onset events registration form and submitted the related clinical data to the Renal Institute of Peking University via email within 1 month. The suspected clinical outcomes were then adjudicated by an independent committee consisting of specialist physicians.

\section{Statistical analysis}

All CKD patients were stratified according to tertiles of baseline serum uromodulin levels. Continuous variables are presented as the means and standard deviations, except for highly skewed variables that are shown as median and interquartile ranges (IQR), and categorical variables are presented as proportions. One-way ANOVA was used to compare continuous variables, and Chi squared tests were used to compare categorical variables.
The incidence rates of end-point events (including ESKD, cardiovascular event and all-cause mortality) were calculated as number of events per 100 person-years. We depicted cumulative hazard function for the three events separately according to uromodulin levels by using a Kaplan-Meier curve and compared the event rates by using log-rank test.

To investigate the association between serum uromodulin and outcomes, Cox proportional hazards regression models were used to estimate hazards ratios (HRs) and 95\% confidence intervals (CIs). We found that the risk of ESKD was linearly increased through the decline of uromodulin as shown in the linear spline analysis (Additional file 1: Figure S1), so we treated uromodulin either as a categorical variable (using the highest tertile as the reference) or a continuous variable (per standard deviation change) to represent the exposure variable. Multivariable models were constructed to adjust for potential confounding variables of the adverse outcomes, including age (continuous), gender (male vs. female), body-mass index (continuous), current smoker (yes vs. no), previous history of cardiovascular disease (yes vs. no), systolic blood pressure (continuous), using anti-hypertensive medications in the past 2 weeks (yes vs. no), diabetes (yes vs. no), prealbumin (continuous), logarithm transformed low-density lipoprotein cholesterol, high-density lipoprotein cholesterol [20], triglyceride, high-sensitivity C-reactive protein, urinary albumin/creatinine ratio (all in continuous), and eGFR (continuous). The missing values were filled before they were entered in the regression model. The proportional hazards assumption was assessed via Kaplan-Meier curves using log-log plots. We fitted logistic regression model by using the same covariates in the Cox regression model and calculated area under receiver operating characteristic curve (AUC). We compared AUCs inclusion or exclusion of serum uromodulin in the model with traditional cardiovascular risk factors, eGFR and ACR, in order to evaluate the change in discriminating ability for ESKD after inclusion of serum uromodulin. Statistical analyses were performed using the SAS software (version 9.4, SAS institute, CA, USA). $P<0.05$ (two-sided) was considered statistically significant.

\section{Results}

Baseline characteristics by serum uromodulin levels

Among the 2652 CKD patients included in our study, 1548 (58.4\%) were male, and 1104 (41.6\%) were female, with an age of $48.7 \pm 13.8$ years. The baseline eGFR was $49.6 \pm 29.4 \mathrm{~mL} / \mathrm{min} / 1.73 \mathrm{~m}^{2}$. A total of $788(29.7 \%)$ participants had an eGFR greater than $60 \mathrm{~mL} / \mathrm{min} / 1.73 \mathrm{~m}^{2}$ at baseline. Altogether, 1053 (39.7\%) and 811 (30.6\%) patients were in CKD stages 3 and 4, respectively. 
The median level of serum uromodulin was $77.2 \mathrm{ng} / \mathrm{mL}$ (IQR 48.3-125.9 ng/mL) in 2652 CKD patients. The levels in the three etiologic types of CKD were $100.4 \pm 65.6 \mathrm{ng} /$ $\mathrm{mL}$ in glomerular diseases, $69.0 \pm 40.6 \mathrm{ng} / \mathrm{mL}$ in tubulointerstitial diseases and $73.4 \pm 51.4 \mathrm{ng} / \mathrm{mL}$ in other or unknown causes, respectively $(P<0.001)$. The baseline characteristics of CKD patients according to tertiles of the serum uromodulin levels are presented in Table 1. Compared with patients with higher serum uromodulin levels, those with lower uromodulin levels were older, had a higher proportion of previous history of smoking, diabetes, and cardiovascular disease, higher proportion of current use of antihypertensive medications, and had higher levels of blood pressure, triglyceride, high-sensitivity C-reactive protein and urinary albumin/creatinine ratio but lower levels of total cholesterol and eGFR. The patients with missing value in the clinical characteristics tended to have a lower uromodulin level in our study. For example, the uromodulin levels were $79.20 \mathrm{ng} / \mathrm{mL}$ and
$92.19 \mathrm{ng} / \mathrm{mL}$, respectively, among those with and without missing value of systolic blood pressure $(P<0.001)$. In addition, we found a positive correlation between serum uromodulin and eGFR in multivariable linear correlation analysis $(\mathrm{r}=0.68, P<0.001)$.

\section{The incidence rates of the end-point events according to levels of serum uromodulin}

The incidence rates of end-point events according to levels of serum uromodulin are shown in Table 2. During the median follow-up of 53.6 (IQR 44.0-64.0) months, there were 404 ESKD, 189 cardiovascular events and 69 deaths occurred. ESKD, cardiovascular events and death rates were $3.60,1.60$ and 0.57 per 100 person-years, respectively. Higher incidence rates of all the three endpoint events were seen with the decreased levels of uromodulin (Figs. 1, 2, 3, all P-values for log-rank test $<0.05$ ).

Table 1 Baseline characteristics of the patients by tertiles of serum uromodulin

\begin{tabular}{|c|c|c|c|c|}
\hline \multirow[t]{2}{*}{ Characteristics } & \multirow[t]{2}{*}{ Total $(\mathrm{N}=2652)$} & \multicolumn{3}{|c|}{ Serum uromodulin tertiles $(\mathrm{ng} / \mathrm{mL})$} \\
\hline & & $\leq 52.7(\mathrm{~N}=885)$ & $>52.7-100.8(\mathrm{~N}=881)$ & $>100.8(\mathrm{~N}=886)$ \\
\hline Age (years) & $48.7 \pm 13.8$ & $50.2 \pm 13.6$ & $50.0 \pm 13.2$ & $45.9 \pm 14.1$ \\
\hline Male (n\%) & $1548(58.4 \%)$ & $513(58.0 \%)$ & $534(60.6 \%)$ & $501(56.6 \%)$ \\
\hline Body mass index $\left(\mathrm{kg} / \mathrm{m}^{2}\right)$ & $24.4 \pm 3.6$ & $24.2 \pm 3.7$ & $24.7 \pm 3.7$ & $24.4 \pm 3.5$ \\
\hline Systolic blood pressure (mmHg) & $130.1 \pm 19.3$ & $135.7 \pm 20.5$ & $130.4 \pm 18.4$ & $124.7 \pm 17.7$ \\
\hline Diastolic blood pressure (mmHg) & $81.3 \pm 11.7$ & $83.6 \pm 12.4$ & $81.6 \pm 11.7$ & $78.8 \pm 10.4$ \\
\hline Smoking status (n\%) & $907(38.1 \%)$ & $325(42.4 \%)$ & $300(38.2 \%)$ & $282(34.0 \%)$ \\
\hline Diabetes (n\%) & $516(19.6 \%)$ & $178(20.3 \%)$ & $202(23.1 \%)$ & $136(15.4 \%)$ \\
\hline $\begin{array}{l}\text { Using anti-hypertensive medications in the past } 2 \text { weeks } \\
(\mathrm{n} \%)\end{array}$ & $1488(73.2 \%)$ & $540(82.3 \%)$ & $524(76.7 \%)$ & $424(61.1 \%)$ \\
\hline Cardiovascular disease (n\%) & $293(12.2 \%)$ & $121(15.6 \%)$ & $114(14.2 \%)$ & $58(7.0 \%)$ \\
\hline Triglyceride (mmol/L) & $1.8(1.3,2.6)$ & $1.8(1.3,2.6)$ & $1.8(1.3,2.7)$ & $1.7(1.2,2.4)$ \\
\hline Total cholesterol (mmol/L) & $4.8(4.0,5.8)$ & $4.5(3.7,5.4)$ & $4.9(4.1,5.9)$ & $5.0(4.1,6.2)$ \\
\hline High-density lipoprotein cholesterol (mmol/L) & $1.1(0.9,1.3)$ & $1.0(0.9,1.2)$ & $1.1(0.9,1.3)$ & $1.2(1.0,1.4)$ \\
\hline Low-density lipoprotein cholesterol (mmol/L) & $2.6(2.1,3.3)$ & $2.4(2.0,3.0)$ & $2.6(2.1,3.3)$ & $2.8(2.2,3.5)$ \\
\hline Fasting blood glucose (mmol/L) & $4.9(4.4,5.6)$ & $4.9(4.4,5.6)$ & $5.0(4.4,5.7)$ & $4.9(4.4,5.5)$ \\
\hline Prealbumin (g/L) & $326.5 \pm 83.1$ & $348.7 \pm 87.6$ & $327.6 \pm 79.3$ & $303.2 \pm 75.6$ \\
\hline High sensitive-reactive protein (mg/L) & $1.3(0.5,3.0)$ & $1.5(0.6,3.6)$ & $1.4(0.6,3.1)$ & $1.0(0.4,2.5)$ \\
\hline Urinary albumin/creatinine ratio (mg/g) & $473.7(134.1,1046.6)$ & $661.7(233.9,1352.8)$ & $439.9(113.2,969.9)$ & $374.3(100.0,836.6)$ \\
\hline Creatinine $(\mu \mathrm{mol} / \mathrm{L})$ & $173.8 \pm 121.8$ & $247.4 \pm 138.6$ & $165.7 \pm 114.5$ & $108.4 \pm 49.1$ \\
\hline Estimated glomerular filtration rate $\left(\mathrm{mL} / \mathrm{min} / 1.73 \mathrm{~m}^{2}\right)$ & $49.6 \pm 29.4$ & $28.5 \pm 15.0$ & $46.3 \pm 23.0$ & $74.0 \pm 28.0$ \\
\hline \multicolumn{5}{|l|}{ Estimated glomerular filtration rate group $\left(\mathrm{mL} / \mathrm{min} / 1.73 \mathrm{~m}^{2}\right)$} \\
\hline$\geq 90$ & $337(12.7 \%)$ & $5(0.6 \%)$ & $58(6.6 \%)$ & $274(30.9 \%)$ \\
\hline $60-89$ & $451(17.0 \%)$ & $31(3.5 \%)$ & $111(12.6 \%)$ & $309(34.9 \%)$ \\
\hline $45-59$ & 419 (15.8\%) & $73(8.3 \%)$ & $211(24.0 \%)$ & 135 (15.2\%) \\
\hline $30-44$ & 634 (23.9\%) & 211 (23.8\%) & 297 (33.7\%) & $126(14.2 \%)$ \\
\hline $15-29$ & $811(30.6 \%)$ & $565(63.8 \%)$ & $204(23.2 \%)$ & $42(4.7 \%)$ \\
\hline
\end{tabular}

Missing counts: body mass index: 396 , systolic blood pressure: 492 , diastolic blood pressure: 492 , smoking status: 271 , diabetes: 16 , using anti-hypertensive medications in the past 2 weeks: 619 , cardiovascular disease: 240 , triglyceride: 64 , total cholesterol: 68 , high-density lipoprotein cholesterol: 80 , low-density lipoprotein cholesterol: 81 , fasting blood glucose: 96 , prealbumin: 151 , high sensitive-reactive protein: 606 , urinary albumin/creatinine ratio: 299 
Table 2 Association between and the end-point events rates

\begin{tabular}{|c|c|c|c|}
\hline $\begin{array}{l}\text { Serum } \\
\text { uromodulin } \\
\text { tertiles }(\mathrm{ng} / \mathrm{mL})\end{array}$ & $\begin{array}{l}\text { Number } \\
\text { of events }\end{array}$ & $\begin{array}{l}\text { Events } \\
\text { per } 100 \\
\text { person-years }\end{array}$ & $P$ for log-rank \\
\hline \multicolumn{3}{|l|}{ ESRD events } & \multirow[t]{5}{*}{$<0.001$} \\
\hline$\leq 52.7(\mathrm{~N}=885)$ & 267 (30.17\%) & 7.86 & \\
\hline $\begin{array}{c}>52.7-100.8 \\
(N=881)\end{array}$ & $106(12.03 \%)$ & 2.80 & \\
\hline$>100.8(\mathrm{~N}=886)$ & 31 (3.50\%) & 0.77 & \\
\hline Total & 404 (15.23\%) & 3.60 & \\
\hline \multicolumn{3}{|l|}{ Cardiovascular events } & \multirow[t]{5}{*}{$<0.001$} \\
\hline$\leq 52.7(\mathrm{~N}=885)$ & $86(9.72 \%)$ & 2.20 & \\
\hline $\begin{array}{c}>52.7-100.8 \\
\quad(N=881)\end{array}$ & $63(7.15 \%)$ & 1.62 & \\
\hline$>100.8(N=886)$ & $40(4.51 \%)$ & 0.99 & \\
\hline Total & $189(7.13 \%)$ & 1.60 & \\
\hline \multicolumn{3}{|l|}{ All-cause mortality } & \multirow[t]{5}{*}{0.003} \\
\hline$\leq 52.7(\mathrm{~N}=885)$ & 35 (3.95\%) & 0.87 & \\
\hline $\begin{array}{c}>52.7-100.8 \\
(N=881)\end{array}$ & $22(2.50 \%)$ & 0.55 & \\
\hline$>100.8(\mathrm{~N}=886)$ & $12(1.35 \%)$ & 0.29 & \\
\hline Total & $69(2.60 \%)$ & 0.57 & \\
\hline
\end{tabular}

Associations of serum uromodulin with ESKD, cardiovascular events and all-cause mortality

The association of serum uromodulin with outcomes is shown in Table 3. After adjusting for demographic and traditional cardiovascular risk factors, as well as the baseline eGFR levels, baseline serum uromodulin levels were independently associated with the risk of incident ESKD, with an HR of 1.92 (95\% CI 1.26-2.90) in the bottom tertile compared with the top tertile. Every standard deviation increase of uromodulin was associated with a decreased risk of ESKD, with an HR of 0.69 (95\% CI 0.55$0.86)$. However, we did not detect significant associations between serum uromodulin and the risk of cardiovascular events as well as all-cause mortality in multivariable adjusted model. Similar results were found among subgroup of patients with glomerular diseases and tubulointerstitial diseases (Additional file 1: Tables S1, S2).

In the fully adjusted logistic regression model for ESKD, the AUCs with inclusion or exclusion of serum uromodulin level were 0.8623 (95\% CI $0.8438-0.8808$ ) and 0.8601 (95\% CI $0.8413-0.8789$ ), respectively. The difference of the AUCs was 0.0023 (95\% CI -0.0007 to 0.0052) (P-value for the difference $=0.1$.

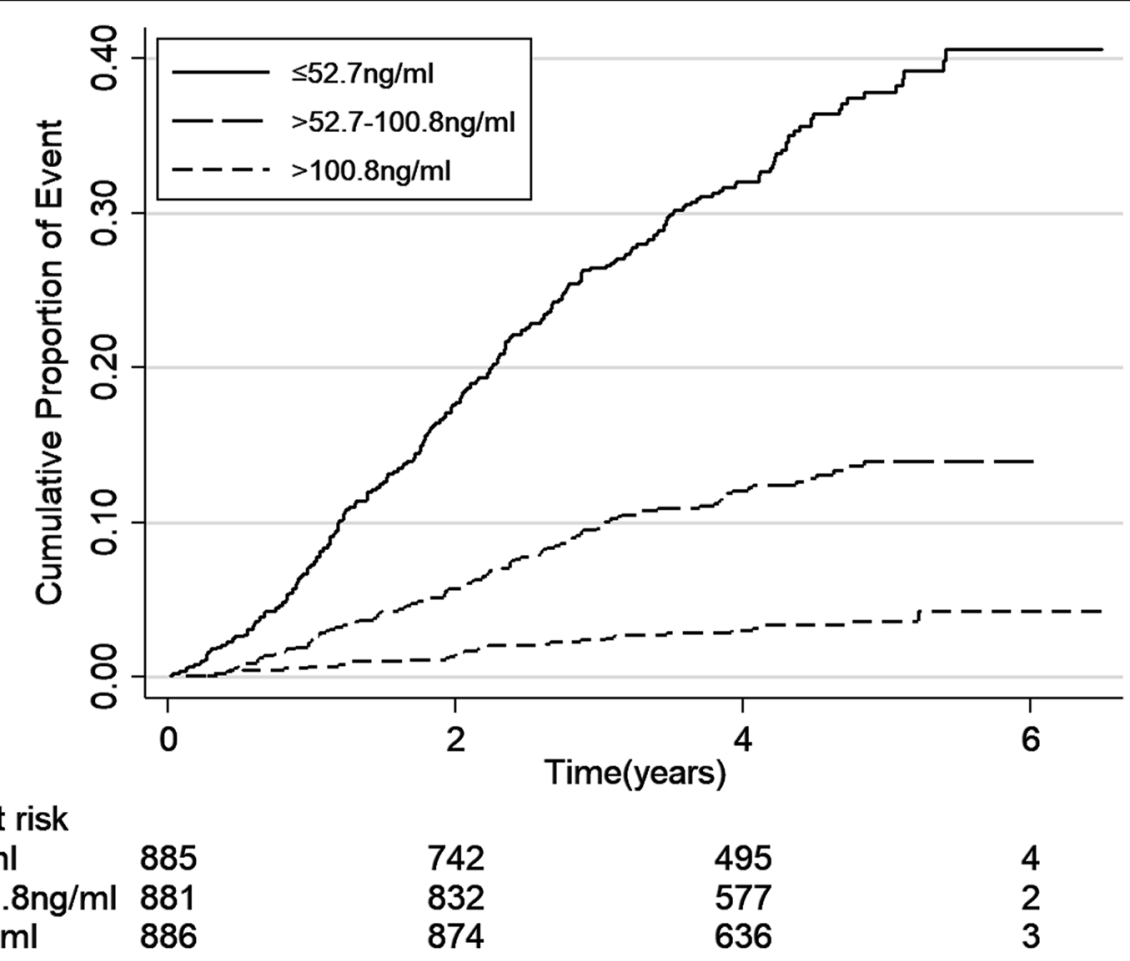

Fig. 1 Kaplan-Meier curve for ESKD events according to tertiles of serum uromodulin

$\begin{array}{llc}\begin{array}{l}\text { Number at risk } \\ \leq 52.7 \mathrm{ng} / \mathrm{ml}\end{array} & 885 & 742 \\ >52.7-100.8 \mathrm{ng} / \mathrm{ml} & 881 & 832 \\ >100.8 \mathrm{ng} / \mathrm{ml} & 886 & 874\end{array}$




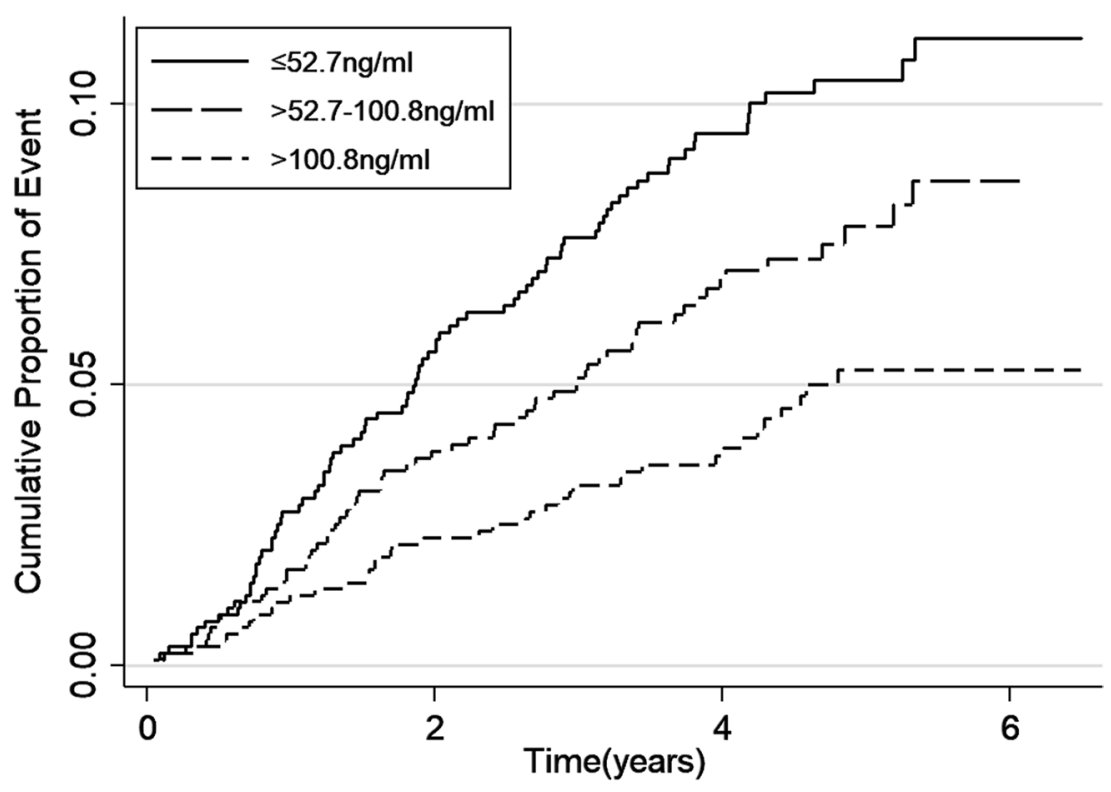

Number at risk $\leq 52.7 \mathrm{ng} / \mathrm{ml}$ 885 $>52.7-100.8 \mathrm{ng} / \mathrm{ml} 881$ $>100.8 \mathrm{ng} / \mathrm{ml}$ 886

837

848

866
627

609

638
5

2

3

Fig. 2 Kaplan-Meier curve for cardiovascular events according to tertiles of serum uromodulin

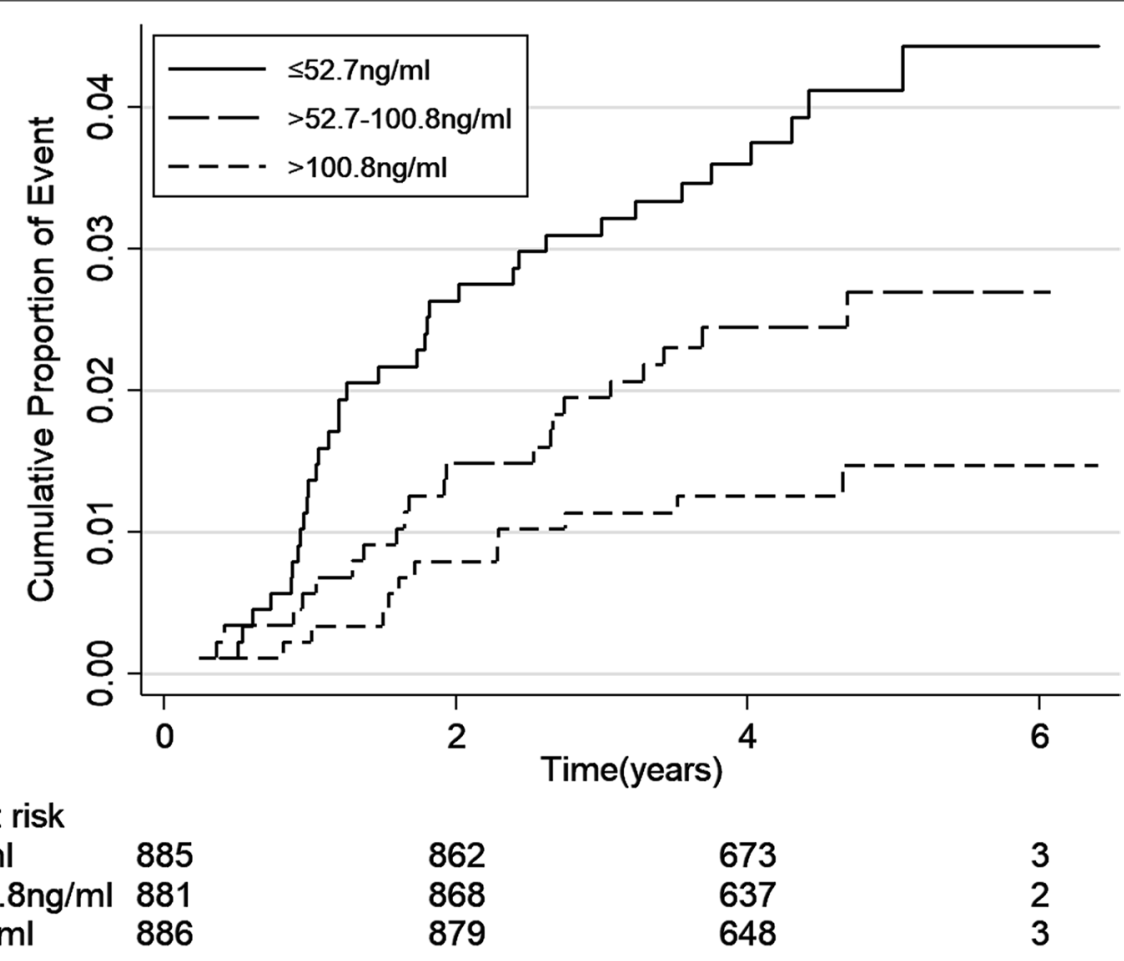

Fig. 3 Kaplan-Meier curve for all-cause mortality according to tertiles of serum uromodulin 
Table 3 Association of serum uromodulin with ESKD, cardiovascular events and all-cause mortality

\begin{tabular}{|c|c|c|c|}
\hline $\begin{array}{l}\text { Serum } \\
\text { uromodulin } \\
\text { tertiles }(\mathrm{ng} / \mathrm{mL})\end{array}$ & $\begin{array}{l}\text { Model } 1 \\
\text { HR }(95 \% \mathrm{Cl})\end{array}$ & $\begin{array}{l}\text { Model } 2 \\
\text { HR }(95 \% \mathrm{Cl})\end{array}$ & $\begin{array}{l}\text { Model } 3 \\
\text { HR }(95 \% \mathrm{Cl})\end{array}$ \\
\hline \multicolumn{4}{|l|}{ ESKD events } \\
\hline$>100.8$ & 1.00 (Ref) & 1.00 (Ref) & 1.00 (Ref) \\
\hline$>52.7-100.8$ & $3.70(2.48,5.54)$ & $3.23(2.15,4.85)$ & $1.36(0.90,2.06)$ \\
\hline$\leq 52.7$ & $10.46(7.20,15.21)$ & $7.47(5.06,11.03)$ & $1.92(1.26,2.90)$ \\
\hline Per SD increase & $0.26(0.21,0.32)$ & $0.31(0.25,0.38)$ & $0.69(0.55,0.86)$ \\
\hline \multicolumn{4}{|c|}{ Cardiovascular events } \\
\hline$>100.8$ & 1.00 (Ref) & 1.00 (Ref) & 1.00 (Ref) \\
\hline$>52.7-100.8$ & $1.37(0.92,2.04)$ & $1.04(0.70,1.56)$ & $0.80(0.52,1.22)$ \\
\hline$\leq 52.7$ & $1.85(1.27,2.70)$ & $1.24(0.83,1.86)$ & $0.81(0.51,1.28)$ \\
\hline Per SD increase & $0.71(0.59,0.87)$ & $0.88(0.72,1.08)$ & $1.14(0.89,1.45)$ \\
\hline \multicolumn{4}{|l|}{ All-cause mortality } \\
\hline$>100.8$ & 1.00 (Ref) & 1.00 (Ref) & 1.00 (Ref) \\
\hline$>52.7-100.8$ & $1.63(0.80,3.29)$ & $1.35(0.65,2.77)$ & $1.04(0.48,2.23)$ \\
\hline$\leq 52.7$ & $2.59(1.34,5.00)$ & $1.94(0.96,3.94)$ & $1.30(0.58,2.93)$ \\
\hline Per SD increase & $0.63(0.45,0.89)$ & $0.73(0.51,1.04)$ & $0.92(0.60,1.41)$ \\
\hline
\end{tabular}

Model 1: Adjusted for age, gender

Model 2: Model 1+current smoker, body-mass index, diabetes, systolic blood pressure, using anti-hypertensive medications in the past 2 weeks, cardiovascular diseases history, logarithm transformed triglyceride, logarithm transformed low-density lipoprotein cholesterol, prealbumin, logarithm transformed high-density lipoprotein cholesterol, logarithm transformed sensitive-reactive protein and logarithm transformed urinary albumin/creatinine ratio

Model 3: Model 2+ estimated glomerular filtration rate

ESKD end stage kidney disease, SD standard deviation

\section{Discussion}

In the current study, we described the association of serum uromodulin and ESKD, cardiovascular events, all-cause mortality in the context of CKD. We found that the baseline lower levels of serum uromodulin were associated with an increased risk of incident ESKD independent of the traditional risk factors for progression of CKD.

Uromodulin is a glycosyl phosphatidylinositol (GPI) linked glycoprotein exclusively synthesized in renal tubular epithelial cells [21]. Most of the uromodulin protein cleaved by proteolysis is released into the urine [22, 23]; a smaller but significant basolateral release of uromodulin is secreted to the tubulointerstitium [3, 24-26] and is detected in the blood. Recently, two SNPs within the promoter region of the $U M O D$ gene were found to be associated with a decline in the occurrence of CKD and a lower urinary uromodulin level $[12,13]$. Previous studies mainly focused on urinary uromodulin excretion $[8,25,27]$, but serum uromodulin has not been investigated widely. Furthermore, serum uromodulin is a stable monomeric antigen and seem to be more reliably measured [28]. Thus, we evaluated whether the level of serum uromodulin was associated with outcomes of CKD in a large, multicenter prospective cohort study of CKD patients.

To the best of our knowledge, the current study is the first prospective one assessing the association between serum uromodulin and kidney disease progression in CKD population. Our results were, to some extent, in line with several recent studies $[17,29]$. A recent crosssectional study by Steubl et al. presented that plasma uromodulin could identify early stages of CKD [29]. Additionally, Leiherer et al. [17] reported that lower levels of serum uromodulin were independently associated with the decline of kidney function and the incidence of CKD in patients with established or suspected stable coronary artery disease. However, most of participants included in their study had normal and moderately reduced kidney function and failed to reach the endpoint of ESKD during follow-up. Thus, we extended the previous observation by a large, prospective Chinese CKD cohort with a broad range of eGFR.

Uromodulin is specifically secreted by renal tubular epithelial cells. Experimental data from Trudu [14] showed that over-expression of uromodulin leads to salt-sensitive hypertension, left ventricular hypertrophy and kidney damage. SNPs leading to overexpression of uromodulin in humans are strongly associated with a greater risk of CKD [13]. The above situation is based on individuals with physically functional kidney and variation of uromodulin exits due to the genetic background among individuals. However, in the setting of abnormal kidney function/kidney damage, the decline in absolute uromodulin excretion was caused by the reduction in functional nephron mass and/or reserve of the tubules $[11,30]$. It is possible that a decline in urinary uromodulin excretion from apical secretion is associated with a decline in basolateral release, as evidenced by a decline in the level of serum uromodulin in CKD patients [31, 32]. Thus, lower levels of serum uromodulin indirectly reflected abnormalities in renal tubulointerstitial function, which is associated with a reduction in erythropoietin production, acid-base homeostasis disequilibrium and mineral metabolism disorder, which therefore links the rapid progress on kidney function.

Although the physiological role of circulating uromodulin remains largely unknown, the present data strengthens the notion that serum uromodulin represents a marker of kidney health independent of markers of the glomerular function and might help to distinguish high-risk CKD patients with rapid progress on kidney function. With regard to the ESKD events, our results only found a trend of improvement in the discriminating ability after inclusion of serum uromodulin in the model with traditional markers for kidney function and 
kidney damage. With regard to the cardiovascular complications, Leiherer et al. and Delgado et al. reported that serum uromodulin could predict the risk of cardiovascular events and all-cause mortality among people with coronary disease $[15,16]$. However, we did not observe similar associations in our study. The different ethnic background and a lower cardiovascular risk profile (younger age, lower levels of blood pressure and lower prevalence of diabetes mellitus) might be the reasons for such inconsistency.

There are some limitations of the current study. First, the cohort has a relatively short duration of follow-up and a limited number of cardiovascular events and death, which limited our power to investigate the association between the levels of uromodulin and cardiovascular disease. Furthermore, some laboratory tests for cardiovascular disease, including NT-proBNP, hs-Troponin and Galectin-binding protein, were not included in our study. Second, although most well-established risk factors of CKD progression were included in the multivariable regression models, the possibility of residual confounding still exists. Finally, considering the baseline characteristics of our study, these results will be primarily applicable to patients seen by nephrologists rather than the large population with CKD in the general population who have lower levels of proteinuria and older age.

\section{Conclusions}

This study represents the first prospective cohort study with a large sample size investigating the association between serum uromodulin and outcomes in CKD population. Serum uromodulin levels are independently associated with incident ESKD.

\section{Additional file}

Additional file 1. Additional figure and tables.

\section{Abbreviations}

CKD: chronic kidney disease; C-STRIDE: The Chinese Cohort Study of Chronic Kidney Disease; ESKD: end-stage kidney disease; HRs: hazard ratios; eGFR: estimated glomerular filtration rate; IQR: interquartile ranges; Cls: confidence intervals; GPL: glycosyl phosphatidylinositol.

\section{Authors' contributions}

$\mathrm{LL}$ searched the literature; JWW analysed the data, interpreted the results. $\mathrm{LL}$, JWW, BXG drafted the manuscript. Kevin He revised the manuscript. MC and LXZ conceived and design the study. MC organised and supervised the study, interpreted the results, and revised the manuscript. $\mathrm{MC}$ and $\mathrm{MHZ}$ obtained funding. Other members collected and analysed the data. MC is the guarantor and takes full responsibility for the work as a whole, including the study design, access to data, and the decision to submit and publish the manuscript. All authors read and approved the final manuscript.

\begin{abstract}
Author details
${ }^{1}$ Renal Division, Department of Medicine, Peking University First Hospital; Institute of Nephrology, Peking University; Key Laboratory of Renal Disease, Ministry of Health of China; Key Laboratory of Chronic Kidney Disease Prevention and Treatment (Peking University), Ministry of Education, Beijing 100034, China. ${ }^{2}$ The First Affiliated Hospital, Baotou Medical College, Baotou 014010, China. ${ }^{3}$ Department of Biostatistics, School of Public Health, University of Michigan, Ann Arbor, MI, USA. ${ }^{4}$ Center for Data Science in Health and Medicine, Peking University, Beijing, China. ${ }^{5}$ Peking-Tsinghua Center for Life Sciences, Beijing, China.
\end{abstract}

\section{Acknowledgements} Not applicable.

\section{Competing interests}

The authors declare that they have no competing interests.

\section{Availability of data and materials}

All data generated or analysed during this study are included in this published article.

\section{Consent for publication \\ Not applicable.}

\section{Ethics approval and consent to participate}

The study was approved by the Ethics Committee of Peking University First Hospital and was in adherence with the Declaration of Helsinki.

\section{Funding}

This study was supported by two grants from the National Key Research and Development Program (Nos. 2016YFC1305405 and 2011BAl10B01), two grants from the National Natural Science Fund (Nos. 81425008 and 81621092), and a grant by Peking University Health Science Center (No. BMU2017CJ002), a grant from the University of Michigan Health System and Peking University Health Sciences Center Joint Institute for Translational and Clinical Research.

\section{Publisher's Note}

Springer Nature remains neutral with regard to jurisdictional claims in published maps and institutional affiliations.

Received: 11 August 2018 Accepted: 13 November 2018

Published online: 19 November 2018

\section{References}

1. Zhang L, Wang F, Wang L, Wang W, Liu B, Liu J, Chen M, He Q, Liao Y, Yu X, Chen N, Zhang JE, Hu Z, Liu F, Hong D, Ma L, Liu H, Zhou X, Chen J, Pan L, Chen W, Wang W, Li X, Wang H. Prevalence of chronic kidney disease in China: a cross-sectional survey. Lancet. 2012;379:815-22.

2. Gansevoort RT, Correa-Rotter R, Hemmelgarn BR, Jafar TH, Heerspink HJ, Mann JF, Matsushita K, Wen CP. Chronic kidney disease and cardiovascular risk: epidemiology, mechanisms, and prevention. Lancet. 2013;382:339-52.

3. Alamartine E, Sauron C, Laurent B, Sury A, Seffert A, Mariat C. The use of the Oxford classification of IgA nephropathy to predict renal survival. Clin J Am Soc Nephrol. 2011;6:2384-8.

4. Hsieh C, Chang A, Brandt D, Guttikonda R, Utset TO, Clark MR. Predicting outcomes of lupus nephritis with tubulointerstitial inflammation and scarring. Arthritis Care Res (Hoboken). 2011;63:865-74.

5. Yu F, Wu LH, Tan Y, Li LH, Wang CL, Wang WK, Qu Z, Chen MH, Gao JJ, Li ZY, Zheng X, Ao J, Zhu SN, Wang SX, Zhao MH, Zou WZ, Liu G. Tubulointerstitial lesions of patients with lupus nephritis classified by the 2003 international society of nephrology and renal pathology society system. Kidney Int. 2010;77:820-9.

6. Mise K, Hoshino J, Ueno T, Hazue R, Hasegawa J, Sekine A, Sumida K, Hiramatsu R, Hasegawa E, Yamanouchi M, Hayami N, Suwabe T, Sawa N, Fujii T, Hara S, Ohashi K, Takaichi K, Ubara Y. Prognostic value of tubulointerstitial lesions, urinary $N$-acetyl- $\beta$-D-glucosaminidase, and urinary 
B2-microglobulin in patients with type 2 diabetes and biopsy-proven diabetic nephropathy. Clin J Am Soc Nephrol. 2016;11:593-601.

7. Bachmann S, Koeppen-Hagemann I, Kriz W. Ultrastructural localization of Tamm-Horsfall glycoprotein (THP) in rat kidney as revealed by protein a gold immunocytochemistry. Histochemistry. 1985;83:531-8.

8. Jennings P, Aydin S, Kotanko P, Lechner J, Lhotta K, Williams S, Thakker RV, Pfaller W. Membrane targeting and secretion of mutant uromodulin in familial juvenile hyperuricemic nephropathy. J Am Soc Nephrol. 2007;18:264-73.

9. Kumar S, Muchmore A. Tamm-Horsfall protein-uromodulin (1950-1990). Kidney Int. 1990;37:1395-401.

10. Dahan K, Devuyst O, Smaers M, Vertommen D, Loute G, Poux JM, Viron B, Jacquot C, Gagnadoux MF, Chauveau D, Büchler M, Cochat P, Cosyns JP, Mougenot B, Rider MH, Antignac C, Verellen-Dumoulin C, Pirson Y. A cluster of mutations in the UMOD gene causes familial juvenile hyperuricemicne phropathy with abnormal expression of uromodulin. J Am Soc Nephrol. 2003;14:2883-93.

11. Hart TC, Gorry MC, Hart PS, Woodard AS, Shihabi Z, Sandhu J, Shirts B, Xu L, Zhu H, Barmada MM, Bleyer AJ. Mutations of the UMOD gene are responsible for medullary cystic kidney disease 2 and familial juvenile hyperuricaemic nephropathy. J Med Genet. 2002;39:882-92.

12. Köttgen $A$, Hwang SJ, Larson MG, Van Eyk JE, Fu Q, Benjamin EJ, Dehghan A, Glazer NL, Kao WH, Harris TB, Gudnason V, Shlipak MG, Yang Q, Coresh J, Levy D, Fox CS. Uromodulin levels associate with a common UMOD variant and risk for incident CKD. J Am Soc Nephrol. 2010;21:337-44.

13. Köttgen A, Glazer NL, Dehghan A, Hwang SJ, Katz R, Li M, Yang Q, Gudnason V, Launer LJ, Harris TB, Smith AV, Arking DE, Astor BC, Boerwinkle E, Ehret GB, Ruczinski I, Scharpf RB, Chen YD, de Boer IH, Haritunians T, Lumley T, Sarnak M, Siscovick D, Benjamin EJ, Levy D, Upadhyay A, Aulchenko YS, Hofman A, Rivadeneira F, Uitterlinden AG, van Duijn CM, Chasman DI, Paré G, Ridker PM, Kao WH, Witteman JC, Coresh J, Shlipak MG, Fox CS. Multiple loci associated with indices of renal function and chronic kidney disease. Nat Genet. 2009;41:712-7.

14. Trudu M, Janas S, Lanzani C, Debaix H, Schaeffer C, Ikehata M, Citterio L, Demaretz S, Trevisani F, Ristagno G, Glaudemans B, Laghmani K, Dell'Antonio G, Loffing J, Rastaldi MP, Manunta P, Devuyst O, Rampoldi L. Commonnon coding UMOD gene variants induce salt-sensitive hypertension and kidney damage by increasing uromodulin expression. Nat Med. 2013;19:1655-60.

15. Leiherer A, Muendlein A, Saely CH, Ebner J, Brandtner EM, Fraunberger $\mathrm{P}$, Drexel H. Serum uromodulin is a predictive biomarker for cardiovascular events and overall mortality in coronary patients. J Cardiol. 2017;231:6-12.

16. Delgado GE, Kleber ME, Scharnagl H, Krämer BK, März W, Scherberich JE. Serum uromodulin and mortality risk in patients undergoing coronary angiography. J Am Soc Nephrol. 2017;28:2201-10.

17. Leiherer A, Muendlein A, Saely CH, Brandtner EM, Geiger K, Fraunberger $P$, Drexel $H$. The value of uromodulin as a new serum marker to predict decline in renal function. J Hypertens. 2018;36:110-8.

18. Gao B, Zhang L, Wang H, Zhao M. Chinese cohort study of chronic kidney disease: design and methods. Chin Med J. 2014;127:2180-4.

19. Ma YC, Zuo L, Chen JH, Luo Q, Yu XQ, Li Y, Xu JS, Huang SM, Wang LN, Huang W, Wang M, Xu GB, Wang HY. Modified glomerular filtration rate estimating equation for Chinese patients with chronic kidney disease. J Am Soc Nephrol. 2006;17:2937-44.

20. Myers GL, Cooper GR, Winn CL, Smith SJ. The Centers for Disease ControlNational Heart, lung and blood institute lipid standardization program. An approach to accurate and precise lipid measurements. Clin Lab Med. 1989;9:105-35.

21. Serafini-Cessi F, Malagolini N, Hoops TC, Rindler MJ. Biosynthesis and oligosac-charide processing of human Tamm-Horsfall glycoprotein permanently expressed in HeLa cells. Biochem Biophys Res Commun. 1993;194:784-90

22. Serafini-Cessi F, Malagolini N, Cavallone D. Tamm-Horsfall glycoprotein: biology and clinical relevance. Am J Kidney Dis. 2003;42:658-76.

23. Fukuoka S, Kobayashi K. Analysis of the C-terminal structure of urinary Tamm-Horsfall protein reveals that the release of the glycosyl phosphatidylinositol anchored counterpart from the kidney occurs by phenylalanine-specific proteolysis. Biochem Biophys Res Commun. 2001;289:1044-8.

24. Cavallone D, Malagolini N, Serafini-Cessi F. Echanism of release of urinary Tamm-Horsfall glycoprotein from the kidney GPI-anchored counterpart. Biochem Biophys Res Commun. 2001;280:110-4.

25. Bleyer AJ, Hart TC, Shihabi Z, Robins V, Hoyer JR. Mutations in the uromodulin gene decrease urinary excretion of Tamm-Horsfall protein. Kidney Int. 2004;66:974-7.

26. El-Achkar TM, McCracken R, Rauchman M, Heitmeier MR, Al-Aly Z, Dagher PC, Wu XR. Tamm-Horsfall protein-deficient thick ascending limbs promote injury to neighboring S3 segments in an MIP-2-dependent mechanism. Am J Physiol Renal Physiol. 2011;300:F999-1007.

27. Garimella PS, Biggs ML, Katz R, IX JH, Bennett MR, Devarajan P, Kestenbaum BR, Siscovick DS, Jensen MK, Shlipak MG, Chaves PH, Sarnak MJ. Urinary uromodulin, kidney function, and cardio-vascular disease in elderly adults. Kidney Int. 2015;88:1126-34.

28. Youhanna S, Weber J, Beaujean V, Glaudemans B, Sobek J, Devuyst O. Determination of uromodulin in human urine. Influence of storage and processing. Nephrol Dial Transplant. 2014;29:136-45.

29. Steubl D, Block M, Herbst V, Nockher WA, Schlumberger W, Satanovskij R, Angermann S, Hasenau AL, Stecher L, Heemann U, Renders L, Scherberich J. Plasma uromodulin correlates with kidney function and identifies early stages in chronic kidney disease patients. Medicine (Baltimore). 2016;95:e3011.

30. El-Achkar TM, Wu XR. Uromodulin in kidney injury: an instigator, bystander, or protector? Am J Kidney Dis. 2012;59:452-61.

31. Fedak D, Kuźniewski M, Fugiel A, Wieczorek-Surdacka E, PrzepiórkowskaHoyer B, Jasik P, Miarka P, Dumnicka P, Kapusta M, Solnica B, Sułowicz W. Serum uromodulin concentrations correlate with glomerular filtration rate in patients with chronic kidney disease. Pol Arch Med Wewn. 2016;126:995-1004.

32. Thornley C, Dawnay A, Cattell WR. Human Tamm-Horsfall glycoprotein urinary and plasma levels in normal subjects and patients with renal disease determined by a fully validated radioimmunoassay. Clin Sci (Lond). 1985;68:529-35.

Ready to submit your research? Choose BMC and benefit from:

- fast, convenient online submission

- thorough peer review by experienced researchers in your field

- rapid publication on acceptance

- support for research data, including large and complex data types

- gold Open Access which fosters wider collaboration and increased citations

- maximum visibility for your research: over 100M website views per year

At BMC, research is always in progress.

Learn more biomedcentral.com/submissions 